\title{
CLONAGEM DO JAMBEIRO-ROSA (Syzygium malacensis) POR ESTAQUIA DE RAMOS ENFOLHADOS ${ }^{1}$
}

\author{
ANTONIO BALDO GERALDO MARTINS'; FABIANA ANDRÉIA GRACIANO; \\ ANA VERUSKA CRUZ DA SILVA ${ }^{4}$
}

\begin{abstract}
RESUMO - O jambeiro-rosa é uma fruteira exótica que representa uma alternativa aos fruticultores, devido às características organolépticas de seus frutos. Em virtude da segregação genética e ausência de sementes em vários clones, procurou-se, neste trabalho, estudar a propagação vegetativa, utilizando-se de estacas com folhas e a influência do tratamento com AIB. O trabalho foi realizado na Área experimental de fruticultura da Faculdade de Ciências Agrárias e Veterinárias - UNESP, Câmpus de Jaboticabal, São Paulo, no período de outubro de 1998 a março de 1999, tendo como objetivo avaliar a capacidade de enraizamento de estacas com folhas apicais e subapicais de jambeiro-rosa com a utilização de diferentes concentrações de ácido indolbutírico (AIB). O delineamento experimental utilizado foi o inteiramente casualizado, em um esquema fatorial 2 x 4 ( 2 tipos de estacas e 4 concentrações de AIB), com 4 repetições e 10 estacas por parcela, num total de 320 estacas. As concentrações de AIB utilizadas foram: 0; 100; 200 e 400 mg. $\mathrm{L}^{-1}$, e as estacas foram colocadas em imersão lenta por 14 horas, no escuro. Foram avaliados os percentuais de sobrevivência das estacas e enraizamento das estacas, número médio de raízes e brotos por estaca, e comprimento médio dos brotos. Observou-se que o jambeiro-rosa pode ser propagado por estacas com folhas apicais sem a utilização de AIB.
\end{abstract}

Termos para Indexação: enraizamento, AIB

\section{CLONING ROSE APPLE (Syzygium malacensis) BY CUTTING OF LEAVES BRANCHES}

\begin{abstract}
The exotic Syzygium malacensis is a potential alternative for fruit growers due to its fruits characteristics. Using apical and sub apical leaved cuttings, this paper intended to study their vegetative propagation and the IBA influence over them for there are many seedless clones and genetic segregation. The work has been done in the experimental area of fruit growing of Faculdade de Ciências Agrárias e Veterinárias - UNESP, Jaboticabal Campus, São Paulo, within the period of October 1998 and march 1999 , aiming to evaluate the rooting capability of apical and sub apical leaved cuttings, using different concentrations of indolbutiric acid IBA. The experimental delineation used was the one fully casual and the analysis suggested the factorial scheme $2 \mathrm{x} 4$ ( 2 types of cuttings and 4 IAB concentrations) with 4 repetitions and 10 cuttings per parcel, in a total of 320 cuttings. The IBA used concentrations were: 0, 100, 200 and $400 \mathrm{mg} . \mathrm{L}-1$ and the cuttings were placed in slow immersion for 14 hours, in the dark. The analysis were made for: cuttings survival percentage, cuttings rooting percentage, average number per cutting, root average length, bud average length, bud average number per cuttings. According to the analysis, it can be inferred that the Syzygium malacensis can be produced through apical leaved cutting without the usage of IBA.
\end{abstract}

Index of terms: rooting, IBA.

\section{INTRODUÇÃO}

O jambeiro-rosa (Syzygium malacensis) é das Índias Orientais. Foi classificado como planta pertencente ao gênero Eugenia por Popenoe (1974), porém uma outra classificação foi sugerida por Calabrese (1978), citando-o como pertencente ao gênero Syzygium, sendo melhor denominado Syzygium malacensis.

A planta pode atingir até 20 metros de altura, possuindo ramificação densa, com flores de cor verde-esbranquiçada e com numerosos estames. Os frutos são quase esféricos, de coloração amarela ou rosada, com polpa delgada, branca, doce e aromática, um pouco acidulada, contendo ou não uma única semente (Benza, 1993).

No jambeiro-rosa, é comum encontrar frutos em que não ocorreu a formação de sementes; assim sendo, torna-se necessário que a propagação comercial seja por processos vegetativos.

A propagação do jambeiro-rosa através de sementes é muito utilizada (Gomes, 1984). Porém, esse é um método inviável, devido a problemas de segregação genética, e ao longo período que as plantas levam para atingir a idade de produção e a pouca ou nenhuma disponibilidade de sementes.

Os processos vegetativos podem ser utilizados com grande vantagem, e um dos métodos possíveis de utilização para a

1 Trabalho ${ }^{\circ}$ 016/2000. Recebido: 11/01/2001. Aceito para publicação: 07/07/2001.

2 Eng $^{\mathrm{os}}$. Agrônomo, Dsc., Prof. do Dept ${ }^{\circ}$ de Produção Vegetal da FCAV/UNESP - Campus de Jaboticabal. Tel.: 3203.2500 (Ramal 266). E-mail: baldo@fcav.unesp.br

3 Eng $^{a}$ Agrônoma. Dept ${ }^{0}$ de Produção Vegetal da FCAV/UNESP - Campus de Jaboticabal - Tel.: 3203.2500 (Ramal 266)

4 Eng ${ }^{a}$ Agrônoma, MSc., Doutoranda em Agronomia: Produção Vegetal - FCAV/UNESP - Campus de Jaboticabal. FCAV/UNESP. Depto. de Produção Vegetal. Rodovia Prof. Paulo Donato Castellane, Km 5. CEP. 14870-000 Jaboticabal - SP. Tel.: 3203.2500 (Ramal 266) E-mail: veruska@fcav.unesp,br 
produção de mudas é a estaquia. Este método permite a obtenção de plantas idênticas à planta matriz e com um período de tempo curto para atingir a idade de produção (Hartmann e Kester, 1978; Donadio et al., 1992).

A procura pela diversificação de culturas propiciou um aumento do interesse pelo cultivo de fruteiras exóticas. O Brasil possui características edafoclimáticas que lhe conferem grande potencial para o cultivo de diversas espécies de fruteiras exóticas, pois contém uma diversidade muito grande de tipos de solos e temperaturas que favorecem o cultivo de espécies frutíferas tropicais, subtropicais e temperadas (Simão, 1998).

O presente trabalho teve como objetivo avaliar a capacidade de enraizamento de estacas com folhas apicais e subapicais de jambeiro-rosa tratadas com diferentes concentrações de ácido indolbutírico (AIB).

\section{MATERIAL E MÉTODOS}

$\mathrm{O}$ experimento foi conduzido na área experimental de fruticultura da Faculdade de Ciências Agrárias e Veterinárias UNESP, Câmpus de Jaboticabal. A área está localizada a $21^{\circ} 15^{\prime} 22^{\prime \prime}$ de latitude Sul e 48 $15^{\prime} 58^{\prime \prime}$ de longitude Oeste, com altitude média de $590 \mathrm{~m}$. O clima da região, segundo a classificação de Köppen (1948), é o Cwa, caracterizado como subtropical temperado, com precipitação média anual de 1400 $\mathrm{mm}$, com estiagem no inverno e temperatura média anual de 20 ${ }^{\circ} \mathrm{C}$, com médias máximas e mínimas de $24{ }^{\circ} \mathrm{C}$ e $18,5{ }^{\circ} \mathrm{C}$, respectivamente.

A planta matriz encontrava-se com 15 anos de idade, desenvolvendo-se em Latossolo Vermelho-Escuro, de textura média.

Foram utilizadas estacas com folhas apicais e subapicais da planta, com aproximadamente $15 \mathrm{~cm}$ de comprimento, as quais foram cortadas em bisel na parte inferior, logo abaixo da última gema basal e um corte reto logo acima da última gema apical da estaca, mantendo-se um par de folhas por estaca. O preparo das estacas foi realizado no período da tarde do dia 14 de outubro de 1998.

As soluções foram preparadas através da dissolução de ácido indolbutírico (AIB) em álcool $50 \%$ para a obtenção das concentrações de AIB.

Após o preparo das soluções, as estacas foram separadas em apicais e subapicais em feixes com 10 estacas, colocadas com a base na solução-tratamento $(0 ; 100 ; 200$ e 400 mg.L-1 $)$ e deixadas em imersão lenta por um período de 14 horas, sendo mantidas no escuro.

As estacas foram colocadas em caixa de madeira com dimensões de $45 \mathrm{~cm} \times 24 \mathrm{~cm} \times 10 \mathrm{~cm}$, sendo o fundo forrado com papel jornal e preenchido com vermiculita de textura média, que foi posteriormente umedecida. Colocaram-se as estacas no substrato, sendo enterrados dois terços do seu comprimento.

As caixas com as estacas foram mantidas em câmara de nebulização intermitente com intervalos regulados por "timer" em 30 segundos, com nebulização, e 90 segundos, sem nebulização, sob ripado com $50 \%$ de luz natural.

As observações para a avaliação do enraizamento foram realizadas 60 dias após o preparo das estacas.

No momento da avaliação, foram observadas todas as estacas quanto a : porcentagem de sobrevivência e enraizamento, número médio de raiz por estaca e comprimento médio das raízes $(\mathrm{cm})$.

As estacas enraizadas foram transplantadas para saco plástico com substrato de solo + areia + EC (esterco de curral bem curtido) na proporção 3:1:1, sendo avaliadas após 90 dias do transplante quanto ao: comprimento $(\mathrm{cm})$ e número médio dos brotos por estaca.

O delineamento experimental utilizado foi o inteiramente casualizado, com 4 repetições, sendo cada parcela constituída por 10 estacas. A análise do experimento foi em um esquema fatorial 2 x 4 ( 2 tipos de ramos e 4 números de concentrações de AIB).

\section{RESULTADOS E DISCUSSÃO}

As estacas apicais apresentaram maior porcentagem de sobrevivência, diferindo significativamente das estacas subapicais, com médias de $72,96 \%$ e de $39,91 \%$, respectivamente (FIGURA 1).

As concentrações de AIB utilizadas influenciaram significativamente na porcentagem de sobrevivência. Os melhores resultados foram obtidos quando não se trataram as estacas com o regulador de crescimento, e a média encontrada para o tratamento foi de $75,36 \%$; observa-se, ainda, um decréscimo na porcentagem de sobrevivência à medida que aumentou a concentração de AIB.

A interação entre o tipo de estaca e concentração de AIB utilizada não foi significativa a $5 \%$ de probabilidade na porcentagem de sobrevivência das estacas.

Verificou-se, através da análise estatística, que o tipo de estaca diferiu significativamente, e a estaca apical apresentou maior porcentagem de enraizamento - 63\% (FIGURA 2).

$\mathrm{O}$ tratamento que apresentou os melhores resultados foi à testemunha, com uma porcentagem de enraizamento superior $(55,18 \%)$, diferindo somente do tratamento em que se utilizou AIB na concentração de $400 \mathrm{mg} . \mathrm{L}^{-1} \mathrm{e}$ não apresentando diferença significativa em relação às concentrações de 100 e 200 mg.L $\mathrm{L}^{-1}$ de AIB (FIGURA 2).

Realizou-se o desdobramento dos graus de liberdade dos tratamentos por ter havido interação entre as variáveis. Nota-se que não houve interação de doses com as estacas apicais; contudo, quando se trata das subapicais, tem-se uma queda na taxa de enraizamento quando se faz o tratamento das estacas com o regulador testado.

O teste de médias, referente ao estudo do efeito dos tipos de estacas dentro de cada dose, mostra um efeito positivo do uso de regulador em estacas herbáceas quando comparado às subapicais. Resultado semelhante foi observado por Nunes (1981), que verificou que a aplicação de AIB não apresentou efeitos positivos na porcentagem de enraizamento de estacas semilenhosas de figueira (Fícus carica), supondo que estas já possuíam os fatores necessários ao enraizamento.

Em relação ao número médio de raízes por estaca, não observou-se diferença significativa. Contudo, a aplicação de AIB aumentou o número de raízes por estaca em todas as concentrações utilizadas, conforme pode ser observado na Figura 3. Efeito semelhante foi encontrado por Silva et al.(1986) que, trabalhando com enraizamento de estacas de diversas cultivares 


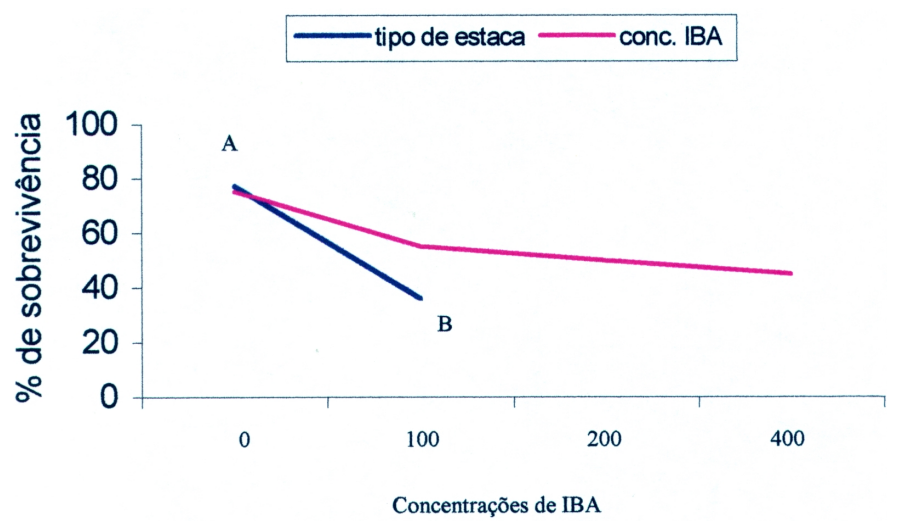

FIGURA 1- Porcentagem de sobrevivência de estacas de jambeiro, em função do tipo de estaca ( A- apical e B- subapical) e das concentrações de AIB testadas

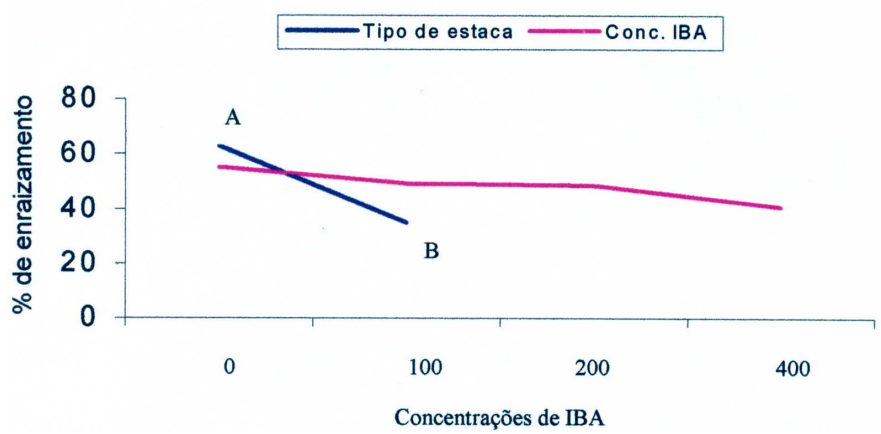

FIGURA 2 - Porcentagem de enraizamento de estacas de jambeiro, em função do tipo de estaca (A- apical e B- subapical) e das concentrações de AIB testadas.

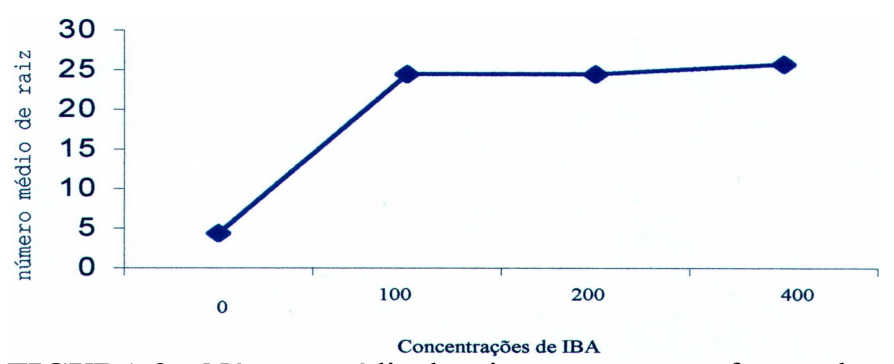

FIGURA 3 - Número médio de raiz por estaca, em função das concentrações de AIB testadas.

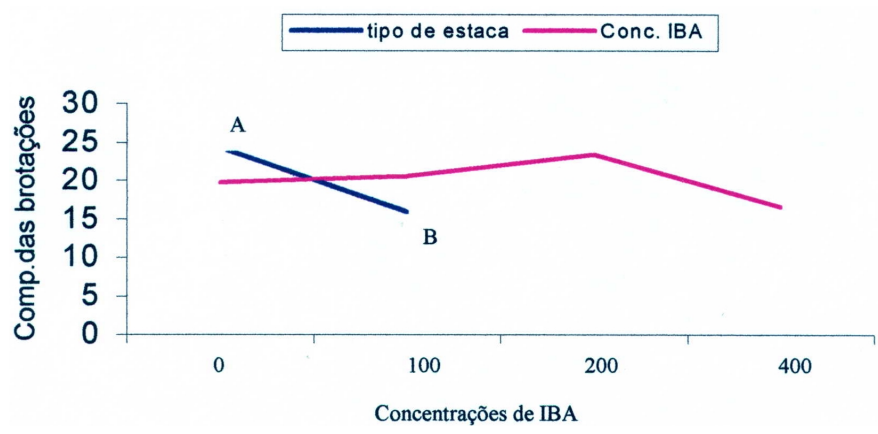

FIGURA 4 - Comprimento das brotações ocorridas nas estacas, em função do tipo (A - apical e B- subapical) e das concentrações de IBA testadas.

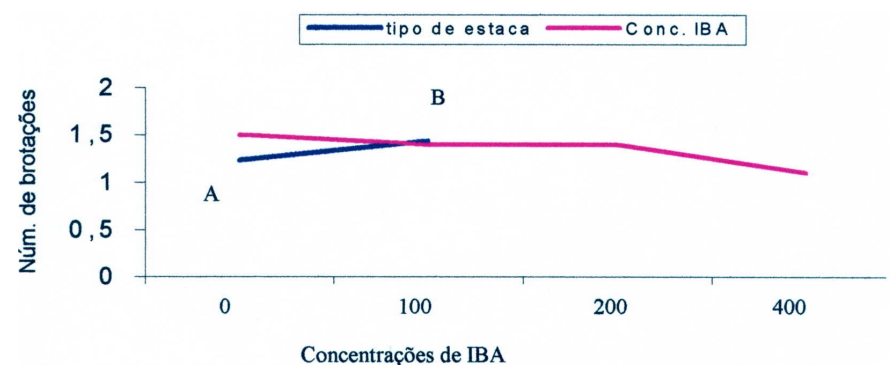

FIGURA 5 - Número de brotações ocorridas nas estacas, em função do tipo (A - apical e B - subapical) e das concentrações de IBA testadas.

de videira (Vitis vinifera), verificou que, naqueles de fácil enraizamento, o AIB age principalmente no aumento do número de raízes. Este aspecto foi observado por Kersten (1990) que, estudando o enraizamento de estacas de ameixeira (Prunus domestica L.), também notou o efeito de AIB no número de raízes. $\mathrm{O}$ mesmo foi verificado em alporques de jambeiro-rosa (Antunes, 1999).

Observou-se também que não houve qualquer diferença com relação ao comprimento médio de raiz nos diferentes tipos de estacas e concentrações de AIB utilizadas. Efeito semelhante foi observado por Ferreira (1994) em trabalhos com estacas de aceroleira (Malpighia glabra L.), constatando que não houve efeito significativo de qualquer tratamento utilizando AIB no comprimento médio das raízes e De Vries e Dubois (1988), trabalhando com estacas de roseira 'Amanda', verificaram que as concentrações de AIB não tiveram efeito significativo no tamanho das raízes.

Sobre o comprimento médio dos brotos, o tipo de estaca diferiu significativamente, ou seja, as estacas apicais apresentaram comprimento médio dos brotos $(24,22 \%)$ maior que as subapicais $(15,91 \%)$, conforme a Figura 4. Observa-se um aumento do comprimento médio dos brotos até a concentração de $200 \mathrm{mg} . \mathrm{L}^{-1}$ de AIB e um decréscimo do comprimento na concentração de $400 \mathrm{mg} . \mathrm{L}^{-1}$.

Também não houve diferença com relação ao número médio de brotos por estaca nos diferentes tipos de estacas e concentrações de AIB (FIGURA 5).

\section{CONCLUSÃO}

O jambeiro-rosa pode ser propagado por estacas com folhas apicais, com sucesso, sem a utilização de AIB.

\section{REFERÊNCIAS BIBLIOGRÁFICAS}

ANTUNES, E.C. Propagação do jambeiro-rosa (Syzygium jambos L. Alston) pelo processo de alporquia. 1999. $42 \mathrm{f}$. Monografia (Trabalho de graduação em Agronomia) - Faculdade de Ciências Agrárias e Veterinárias, Universidade Estadual Paulista, Jaboticabal, 1999.

BENZA, J.C. 143 Frutales nativos. Lima: Ed. Universidad Nacional Agrária La Molina, 1993. 366p. 
CALABRESE, F. Frutticoltura tropicalle y subtropicale. Bologna: Cooperativa Libraria Universitaria Editrice, 1978. 483 p.

DE VRIES, D.P.; DUBOIS, L.A.M. The effect of BAP and IBA on sprouting and adventitious root formation of "Amanda" rose single - node softwood cuttings. Science Horticulturae, Amsterdan, v. 34, p. 115-21, 1988.

DONADIO, L.C. ; MARTINS, A.B.G.; VALENTE, J.P. Fruticultura tropical. Jaboticabal: FUNEP, 1992. 268p.

FERREIRA, R.C. Efeito de auxinas e sacarose no enraizamento de estacas herbáceas de acerola (Malpighia glabra, L.). 1994. 64f. Monografia (Graduação em Agronomia) - Faculdade de Ciências Agrárias e Veterinárias, Universidade Estadual Paulista, Jaboticabal, 1994.

GOMES, R.P. Fruticultura brasileira. 8 ed. São Paulo: Nobel, 1984. 446p.

HARTMANN, H.T.; KESTER, D.E. Propagación de plantas: principios y practices.7. ed. México: Compañía Editorial, 1978. 810 p.

KERSTEN, E. Efeito do boro, zinco e ácido indolbutírico no enraizamento de estacas de $\mathbf{2}$ cultivares de ameixeira (Prunus saliciosa Lindl.) 1990. 109 f. Tese (Doutorado em Agronomia) - Escola Superior de Agricultura "Luiz de Queiroz", Universidade de São Paulo, Piracicaba, 1990.

KÖPPEN, W. Climatologia. México: Fondo de Cultura Econômica, 1948.478p.

NUNES, R.F.M. Influencia do ácido indolbutírico (AIB) no enraizamento de estacas semi-lenhosas de figueira (Fícus carica L.) "Roxo de Valinhos" em condições de nebulização intermitente. In: CONGRESSO BRASILEIRO DE OLERICULTURA, 21., CONGRESSO DA SOCIEDADE BRASILEIRA DE FLORICULTURA E PLANTAS ORNAMENTAIS, 2, 1981, Campinas. Anais... p. 235.

POPENOE, W. Manual of tropical and subtropical frutis. New York: Macmillan, 1974. 474p.

SILVA, A.L. da, FACHINELLO, J.C.; MACHADO, A.A. Efeito do ácido indolbutírico na enxertia e enraizamento da videira. Pesquisa Agropecuária Brasileira, Brasília, v.21, p. 864-71, 1986.

SIMÃO, S. Tratado de Fruticultura. Piracicaba: FEALQ, 1998. $760 \mathrm{p}$. 